\title{
Haití: crisis posdictatorial y transición democrática
}

Jobanna von Grafenstein Gareis

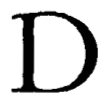

iscutir el "caso" haitiano en este ciclo sobre las' elecciones en América Latina significa referirse al contexto más amplio de una fase de transición que se abrió con la caída del régimen dictatorial de los Duvalier en febrero de 1986. Ciertamente Haití ha conocido en estos últimos cuatro años varias experiencias electorales y se ha dado a conocer un calendario electoral para el año en curso; ${ }^{1}$ sin embargo, para

\footnotetext{
${ }^{1}$ La ponencia fue presentada dos días antes de la renuncia del presidente de facto, Prosper Avril, el 10 de marzo de 1990. El 12 de marzo, Avril abandonó el país y la oposición política nombróa la juez Ertha Pascal Trouillot como presidenta interina. Durante las dos semanas posteriores-lapso en el que se revisó la ponencia-se reforzaron las
}

dar cuenta de las transformaciones que se producen en el país caribeño, no me parece factible recurrir a un análisis electoral en los términos acostumbrados que contemplaría únicamente a las fuerzas políticas en pugna, el sistema de partidos, el discurso político y programas partidarios, el comportamiento electoral de la población, etc. Creo que serían ëstas, sofisticaciones que poco tienen que ver con la realidad haitiana en la que apenas se está formando una sociedad civil (aunque surja con gran vitalidad y pujanza) y persiste una situación que ha sido calificada como de "no-Estado", tal esperanzas de que los sucesos mencionados signifiquen un cambiocual itativoen el desarrollopolítico de la nación caribeña. En este sentido esperamos 
ha sido la degradación de las instituciones estatales. ${ }^{2}$

La problemática de la transición gira, creo yo, alrededor de la liquidación de una dictadura que paralizó el desarrollo político-social durante casi tres décadas, que silenció y aniquiló sístemáticamente toda voz opositora y, sobre todo, que creó poderosos intereses en el seno de un sector social pequeño, pero dispuesto a impedir a toda costa la pérdida de poder y privilegios.

En este sentido pienso que el problema nodal de la crisis posdictatorial reside en la imposibilidad de salir de este "empate" político -al que se refiere Gérard PierreCharles- ${ }^{3}$ entre las nuevas fuerzas democráticas y los herederos de la dictadura, es decir de las fuerzas armadas. El déchoukage (palabra créole que significa "quitar de raíz", en el sentido de una desduvalierización radical) no se ha realizado no obstante los espacios democráticos ganados. La resistencia de las fuerzas dictatoriales y la debilidad de las fuerzas decambio han impedido, hasta ahora, la celebración de lo que se ha llamado "elecciones fundadoras". ${ }^{4}$

que el planteamiento general del presente trabajo (producto del análisis de la situación política anterior a la caída de Avril), relativo a las dificultades de vencer los remanentes dela dictadura duvalierista, se vea superado por el desarrollo de los hechos. Sin embargo, conservamos el texto de la ponencia sin mayores cambios, porque consideramos que contiene elementos válidos para el análisis del desarrollo político de Haiti durante los últimos cuatro años. En su parte final intentamos valorar los sucesos de la primera mitad de marzo en el contexto de la crisis posdictatorial y la transición democrática.

${ }^{2}$ Participación de Michel Hector en la mesa redonda "Hacia la definición de una transición difícil" (coordinada por Suzy Castor), Rencontre, núm. 1, diciembre de 1989, p. 11.

${ }^{3}$ Gérard Pierre-Charles, "The democratic revolution in Haiti", Latin American Perspectives, vol. 15, núm. 3, verano de 1988, p. 74.

${ }^{4}$ Jorge Heine, "Transition to nowhere: How
El siguiente trabajo trata de situar la cuestión electoral en el marco del proceso político-social de los últimos cuatro años y se centra en tres aspectos. El primer punto tiene que ver con los militares y su importancia como defensores del statu quo. Se tratará de seguir el proceso de descomposición que se está produciendo en susfilas y de resaltar su papel como principales oponentes a las elecciones libres, ya que la Constitución de 1987 prohibe el acceso a la presidencia a los ex colaboradores del duvalierismo.

En el segundo punto me ocuparé, también muy brevemente y sin duda de manera incompleta, primaria si se quiere, por ser observadora externa y por depender en gran parte de la prensa extranjera como fuente de información, de este conjunto heterogéneo que son las organizaciones político-sociales en formación.

En tercer lugar veré el deterioro político-social de los últimos meses que pone en entredicho la realización de elecciones abiertas y honestas en el año en curso.

\section{LA DESCOMPOSICIÓN DE LAS FUERZAS ARMADAS}

En 1986, con la huida del presidente vitalicio Jean Claude Duvalier, el general Henri Namphy, comandante de las fuerzas armadas, quedó instalado en el poder a la cabeza del Consejo Nacional de Gobierno (CNG) formado por cinco miembros. ${ }^{5}$ Habiendo guardado cierta neu-

Haiti's democratic transition might have worked", Caribbean Review, vol. xv, núm. 2 , inviemo de 1988, p. 26.

s'sus miembros fueron todavía designados por Baby Doc antes de su huida y contaban con la anuencia del personal de la embajada norteamericana. 
tralidad, el ejército no salió desprestigiado de la última fase de lucha antidictatorial; especialmente Namphy no apareció directamente involucrado en la represión que había ejercido la dictadura. Como es bien sabido, fueron fuerzas paramilitares, los llamados Tontons Macoutes, cuyos 40000 miembros armados aterrorizaban sistemáticamente a la población. Namphy debería fungir como gobernante interino, preparar elecciones generales y permitir la instalación de un gobierno civil. Sin embargo, la vocación "democrática" del general resultó ser poco sólida. Sus declaraciones iniciales en el sentido de que estaba comprometido con "una transición firme e imparcial hacia la democracia" fueron pronto sustituidas por la tesis de que el país se encontraba al borde de la anarquía y de que "la democracia no es para hoy, ni siquiera para mañana". ${ }^{7}$

Entre marzo de 1986 y junio de 1987, el CNG intentaba mediar entre las demandas de cientos de organizaciones políticas y sociales y las presiones de los duvalieristas más recalcitrantes y poco dispuestos a ceder poder y privilegios. ${ }^{8}$ Ante el creciente espacio democrático ganado por la naciente sociedad civil, el régimen de Namphy se endureció hacia mediados del 1987. Como veremos más adelante, la escalada de violencia, tolerada si no fomentada por el ejército, culminó en el sangriento aborto de las elecciones generales de noviembre de 1987.

Después de un breve "interregno civil", ejercido por Leslie Manigat entre enero y

${ }^{6}$ Mark D. Danner, "The struggle for a democratic Haiti", The New York Times, 21 de junio de 1987, en ISLA (Information Service of Latin Amerira), junio de 1987, pp. 193-196.

"Jean-Claude Bajeux, "The little game of january 17 th" $^{n}$, Caribbean Review, vol. XVI, núm. 2, invierno de 1988, p.7.

${ }^{8}$ Jorge Heine, op. cit., p. 5. junio de 1988, Namphy volvió al poder, autoproclamándose presidente de la república. Tres meses después, el 17 de septiembre, fue obligado a dimitir por el llamado "movimiento de los sargentos". El nuevo presidente de facto, Prosper Avril, había sido un viejo aliado de la dictadura, a la cual servía como consejero financiero. Había hecho una brillante carrera militar dentro de la guardia presidencial, pero sin haber sido asociado públicamente con los actos de crueldad de los Duvalier. Considerado por la prensa norteamericana como "astuto e inteligente príncipe de intrigas palaciegas" había actuado tras bambalinas. También ha sido calificado como "más inteligente y pragmático que su predecesor, el general Namphy". ${ }^{10}$ En octubre de 1988 y en abril del año siguiente, el nuevo presidente tuvo que enfrentar varias intentonas, hasta que, en julio del mismo año pudo declarar que "había restablecido la cadena de comandos en el ejército". ${ }^{11}$

Si exceptuamos el golpe de junio de 1988-en el que predominó el "castigo" al presidente civil por sus repentinas muestras de independencia-, los repetidos golpes son expresión de los crecientes antagonismos entre los diferentes sectores de las fuerzas armadas. Estas divisiones internas tienen que ver con rivalidades personales entre los oficiales de alta jerarquía; reflejan antagonismos entre militares "macutistas", es decir, integrantes del ala más retrógrada del

\footnotetext{
${ }^{9}$ Joseph B. Treaster "Many in Haiti wonder who is really in charge", The New York Times, 25 de septiembre de1988, en ISLA, septiembre de 1988, p. 171.

10 "Haiti's hopes and general Avril", editorial de The New York Times, 23 de septiembre de1988, en ISLA, septiembre de 1988, p.170.

${ }^{2}$ Howard W. French, "Right groups fault general for Haiti abuses", The New York Times, $17 \mathrm{de}$ septiembre de 1989, en ISLA, septiembre de 1989, p. 137.
} 
ejército, y militares más "modernos" y pragmáticos. Por otra parte juegan un papel importante las pugnas entre los diferentes cuerpos armados (las tropas de elite Leopardos y el Batallón Dessalines, ${ }^{12}$ la guardia presidencial, la policía). Sin embargo, no sólo se disputan cuotas de poder, sino también beneficios económicos, como ingresos provenientes del contrabando, del narcotráfico y de la especulación con productos básicos que se adquieren a precios controlados y cuya reventa se ha convertido en el negocio preferido de los integrantes del ejército. ${ }^{13}$

En el proceso de descomposición del dominio militar monolítico revistió especial importancia el golpe de septiembre de 1988.

El movimiento de los sargentos, en su mayoría jóvenes y de origen popular, permite por lo menos dos interpretaciones, no necesariamente excluyentes. Por un lado fue una protesta en contra de la degradación del ejército que se convirtió en un simple instrumento de represión neoduvalierista, y por el otro puede considerarse como un eco del creciente descontento general sobre el deterioro de las condiciones de vida de las grandes mayorías. Las demandas de los oficiales, encabezados por Joseph Hébreux, incluían la restitución de la Constitución de 1987, suspendida por

\footnotetext{
${ }^{12}$ Ambos cuerpos fueron disueltos después del fracasado golpe del 2 de abril de 1989, en el que estuvieron implicados soldados de estos dos batallones. Sus comandantes, el coronel Himmler Rébu y el general Guy François, fueron arrestados y posteriormente expulsados del país. En esta breve revuelta, la guardia presidencial se mostró leal a Avril.

${ }^{13}$ Don A. Schanche, "Venal Haiti regime perils recovery efforts", Los Angeles Times, 19 de noviembre de 1989, en ISLA, noviembre de 1989 , p. 212.
}

Namphy; la convocación a elecciones libres; la eliminación y el castigo de elementos del ejército identificados con actos de represión violenta y corrupción; mejoras en las condiciones de vida delos soldados y de la población en general. El programa de 20 reformas refleja la adopción de demandas, defendidas hasta entonces sólo por las fuerzas de oposición. El movimiento constituyó un hecho nuevo en la historia político-militar de Haití, que además despertó grandes esperanzas.

La otra "lectura" de los hechos insólitos de septiembre-octubre de 1988 tiene que ver con la virtual bancarrota del Estado haitiano. Reasegurarse el apoyo financiero de Estados Unidos, suspendido después de los sucesos sangrientos de noviembre de 1987 , se convirtió en una necesidad imperiosa. ${ }^{14}$ Pero había que satisfacer ciertas condiciones que incluían muestras efectivas de una mayor democratización, así como pasos concretos en la lucha contra el narcotráfico. Para ello se hizo indispensable sustituir a Namphy por una figura menos corrupta $\mathrm{y}$ con vínculos menos evidentes con los

${ }^{14}$ En noviembre de 1987 fueron suspendidos 78.7 millones de dólares de ayuda directa aprobada para el añofiscal en curso.Quedaron intactos el programa antinarcóticos; 22.7 millones de dólares para organizaciones privadas, comprometidas con esfuerzos en contra de la pobreza y 7.8 millones en alimentos, distribuidos por dichas organizaciones, The New York Times, 9 de enero de 1988. Desde la suspensión de la ayuda norteamericana y la decisión del Banco Mundial y del FMIde retener alrededor de 40 millones de dólares en préstamos y donaciones, el déficit público aumentó de 25 a 40 millones de dólares. Las reservas nacionales cayeron de 30 a seis o siete millones, suficientes para cubrir por un mes las necesidades de combustible y cereales, Joseph B. Treaster, "Haitians see financial crisis and plead for aid", The New York Times, 24 de septiembre de 1988, en ISLA, septiembre de 1988, p. 170. 

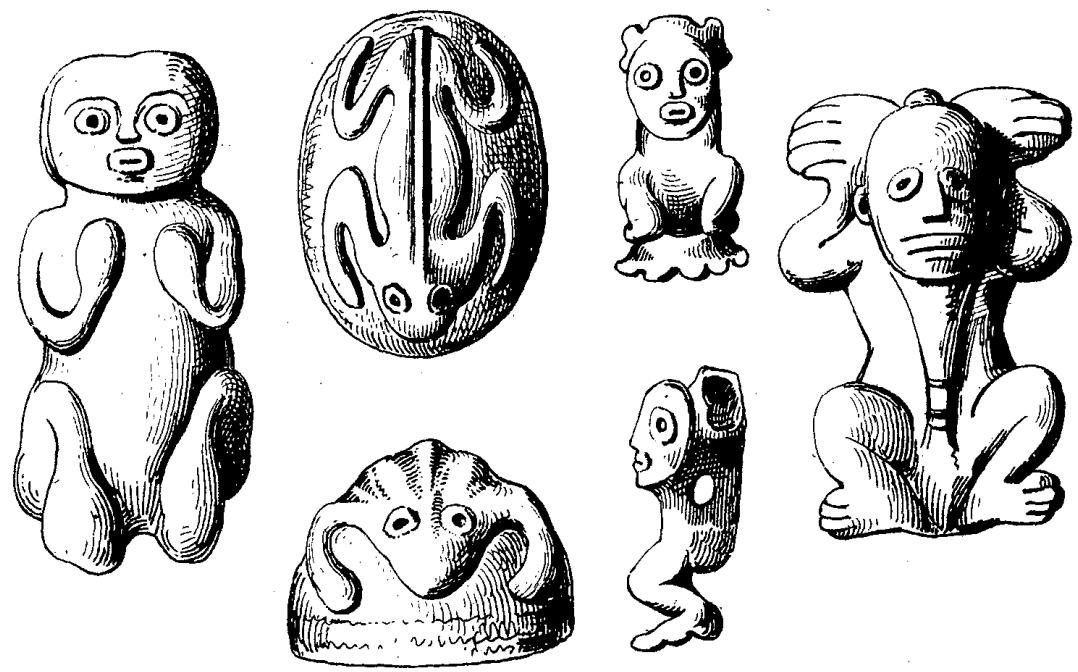

duvalieristas "duros". Prosper Avril parecía cumplir con estas exigencias.

En un primer momento Avril tenía que actuar acorde al espíritu del movimiento reformador: se veía obligado a avalar las múltiples destituciones que llevaron a cabo los oficiales subalternos. Se calcula que fueron retirados entre 60 y 120 mandos militares conocidos como "macutistas". La "purga" afectótambién a directores de empresas estatales cuyos malos manejos eran mâs notorios. Sin embargo, la negativa de Avril de llevar a cabo transformaciones profundas (que hubieran afectado a personas ligadas a él) llevó al frustrado intento de destituirlo a mediados de octubre y al encarcelamiento de 15 oficiales opositores. ${ }^{15}$

${ }^{15}$ Cfr. Clara I. Martínez V., "Los intentos de golpe de Estado en Haití: Crisis social y política en el interior de las fuerzas armadas", en $E l$ Caribe
Por otra parte, Avril dio algunos pasos que reforzaron su imagen de militar reformador: nombróungabinete, integrado por civiles, con excepción del Ministerio de Defensa e Interior, en el que William Regala, uno de los duvalieristas más odiados fue sustituido por el general Carl Dorsainville. El nuevo presidente de facto prometió además tomar medidas en contra del narcotráfico; retiró, aunque después de un momentode vacilación, al coronel Jean-Claude Paul, comandante del Batallón de Dessalines y requerido por un tribunal norteamericano por sus supuestas implicaciones en el nar-

Contemporáneo, núm. 19, julio-diciembre de 1989; Larman Wilson, "Military rule and the hopes for democracy in Haiti: The limits of United States foreign policy", ponencia preparada para el XV Congreso Internacional de LASA, Puerto Rico-Miami, sept.-dic. 1989; Gérard Pierre Charles, El Día, 29 de octubre de 1988, p. 13. 
cotráfico. Poco después, Paul murió en circunstancias no aclaradas.

Avril supo también ganarse el apoyo interno. Se mostró abierto al diálogo, recibiendo a importantes líderes de la oposición. Declaraciones iniciales como las siguientes despertaron además la esperanza de un verdadero cambio: "Mi idea es entrar a la historia como quien salvó al país de la anarquía y dictadura, quien buscó el establecimiento de una democracia irreversible." A la pregunta de si se comprometía a hacer elecciones en un futuro próximo, Avril declaró: "Sí, no hay duda sobre esto. Yo me considero como un lider accidental y provisional del pueblo haitiano. ${ }^{16}$ En enero del año pasado, la credibilidad de Avril alcanzó su punto más alto. La convocación de un foro para la creación de un consejo electoral hacía pensar que quizá su voluntad de cambio era real. La restitución de la Constitución de 1987 (de la cual, sin embargo, 37 artículos quedaron suspendidos) así como el despido de cuatro oficiales, supuestamente ligados al narcotráfico, en marzo de 1989, le valió además comentarios favorables en la prensa y el apoyo con reservas de funcionarios estadunidenses. ${ }^{17}$

${ }^{16}$ Don A. Schanche, "Haiti's leader vows to seek 'durable' democracy", Los Angeles Times, 30 de septiembre de 1988, en ISLA, septiembre de 1988 , p. 178.

${ }^{17}$ El funcionario de la Secretaría de Estado para Asuntos Interamericanos, Richard H. Melton, declaró ante una subcomisión del Congreso norteamericano: "Dadas las decepciones recientes, ningún gobierno militar en Haití debería esperar la completa restitución de la ayuda estadunidense, [pero] el tiempo ha venido para proporcionar al gobierno de Avril modestas sumas de asistencia humanitaria y ayuda especificamente orientada de llevar adelante el proceso electoral", "Cause for Hope", editorial del Miami Herald, 20 de marzode 1989.

\section{EMERGENCLA DE LAS FUERZAS} DEMOCRÁTICAS

Los últimos cuatro años han sido caracterizados por la confrontación entre las fuerzas de cambio y los defensores del statu quo. Una de las facetas más importantes de esta contradicción ha sido la intensa organización político-social que se inició en el último año de la dictadura. Protagonistas de la lucha antidictatorial habían sido los representantes de las Iglesias, los periodistas de la prensa escrita y sobre todo de la radio, los estudiantes universitarios y de enseñanza media, las organizaciones laborales y de profesionistas que, en una oleada de protestas, manifestaciones multitudinarias y huelgas lograron la caída del régimen.

Desde entonces, el movimiento "acéfalo" de fines de la dictadura se ha convertido en un movimiento de muchas cabezas. ${ }^{18}$ Creo que es correcto hablar de avances importantes en la politización y organización de la sociedad civil, aunque el persistente clima de represión ha sido adverso y ha dificultado que la incesante movilización se encauce hacia organizaciones políticas formales y representativas; la falta de recursos y la intimidación constante han frenado el trabajo de proselitismo; un obstáculo poderoso ha sido también el atraso de la población que durante 30 años no conoció lo que pudiera ser la actividad de un partido político independiente, que además ha sido marginado por el altísimo grado de analfabetismo (se estima que afecta entre 70 y $80 \%$ de la población), por el aislamiento geográfico en las zonas rurales y por las extremas condiciones de miseria.

\footnotetext{
${ }^{18}$ Participación de Branly Ogé en "Vers la définition d'une difficile transition", Rencontre, op.cit., p. 29.
} 
En este proceso de concientización política y organización social desempeña un papel importante la Iglesia católica. Desde inicios de los años ochenta, miembros dela base dela Iglesia, de la "pequeña Iglesia", empezaron a manifestar su compromiso con la población que vive en condiciones de pobreza extrema (la mitad está desempleada; el ingreso per cápita de 370 dólares es el más bajo del hemisferio occidental). Las denuncias de la explotacióny opresión, de las que eran víctimas las grandes mayorías, se transformaron pronto en lucha abierta contra la dictadura. Desde su caída, los sacerdotes de la base claman por una desduvalierización efectiva del régimen; exigen el respeto a los derechos básicos y a la dignidad humana; fomentan la organización ciudadana y no dudan en hacer declaraciones muy precisas sobre la situación política.

La autoridad de la Iglesia entre la población es inmensa; por tal razón los sacerdotes.han sido blanco de la represión. Bajo el segundo gobierno de Namphy, en el verano de 1988, fuerzas macutistas incendiaron algunasiglesiase irrumpieron violentamente en la de San Juan Bosco, donde el padre Jean Bertrand Aristide estaba oficiando misa; alrededor de seis personas fueron asesinadas y cerca de 70 resultaron heridas.

También a través de la estación Radio Soleil, la Iglesia ejerce una gran influencia en el país. Otras estaciones independientes han destacado en este proceso de concientización y educación. El uso cada vez mayor del créole en los medios de información ha contribuido a disminuir el aislamiento y la desinformación de las grandes masas.

Por otra parte, desde la caída de la dictadura, han mostrado un considerable poder de convocatoria las organizaciones obreras, sobre todo la Central
Autónoma de Trabajadores de Haití (CATH), que en momentos críticos han logrado paralizar la vida económica del país. También surgieron en los últimos años, combativas organizaciones campesinas que, ante el creciente deterioro de las condiciones de vida de la población rural (dos terceras partes de los 5.5 millones dehabitantes), protestan contra los excesivos impuestos, el acaparamiento de tierras en manos de grandes terratenientes, los abusos de los Tontons Macoutes, que siguen aterrorizando impunemente al campo y se han apoderado de las mejores tierras.

En la profusa organización social han desempeñado un papel importante las organizaciones en defensa de los derechos humanos, agrupaciones de mujeres, profesionistas, estudiantes, asambleas de barrios, etcétera.

En cuanto a la organización de partidos políticos ésta se ha visto favorecida por la relativa apertura desde febrero de 1986; sin embargo, como apuntamos más arriba, su efecto ha sido limitado durante los años pasados. Habría que mencionar por un lado los partidos que habían sido fundados antes de la dictadura, como el Partido Comunista (PUCH) y el Partido del Movimiento Obrero Campesino (MOP); ambos resurgieron después de décadas deilegalidad y represión; por el otro lado están los únicos dos partidos, creados en 1979, que fueron tolerados durante el duvalierismo: el Partido Demócrata Cristiano $(\mathrm{PDCH})$ y el Social Cristiano (PSCH); Leslie Manigat formó en 1979, en el exilio, el Partido de Unión de Demócratas Nacionales Progresistas (RDNP). Después de años de exilio, represión e intimidación, los líderes de los partidos mencionadosempezaron a ser conocidossólo mediante un lento proceso de proselitismo; quien tenía mayor presencia era quizá el lider del PDCH, Sylvio Claude,

\section{2}

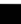


cuyo valor personal en su resistencia a la represión duvalierista le confirió cierto carisma.

Por otra parte están los partidos que surgieron con la apertura, entre los que habría que destacar al Partido Agrícola Industrial (PAIN) de Louis Déjoie, quien cuenta con cierto apoyo popular en el centro y sur del país; el Movimiento para la Restauración de la Democracia en Haití (MIDH) del exfuncionario del Banco Mundial y brevemente ministro de Finanzas de Jean-Claude Duvalier, Marc Bazin; el Partido Nacionalista Progresista Revolucionario (PANPRA) de Serge Gilles, de orientación socialdemócrata; el Movimiento para el Desarrollo Nacional (MDN), encabezado por el sociólogo y ex ministro bajo los Duvalier, Hubert de Ronceray, quien tiene cierta influencia en la pequeña burguesía intelectual: ${ }^{19} \mathrm{el}$ Movimiento para la Organización del País (MOP) de Gérard Philippe Auguste, con influencia en la pequeña burguesía.

La extrema atomización de las organizaciones politico-sociales -son cientos las agrupaciones que existen-ha constituido un obstáculo serio para su incidencia efectiva en la vida nacional y en la lucha contra las fuerzas duvalieristas. Ciertamente se han hecho esfuerzos para superar este estado de pulverización, pero los resultados han sido más bien modestos, por lo menos durante los tres primeros años después de la caída de la dictadura. La cohesión de las alianzas que se han formado ha sido a menudo más aparente que real y su existencia es muchas veces efimera. No obstante, existen agrupaciones importantes como el Congreso Nacional de Movimientos Democráticos Haitianos (KONAKOM) que

${ }^{19}$ Gérard Pierre-Charles, "Un reto dificil: la construcción de la democracia en Haití", Revista Mexicana de Sociología, año xıviI, núm. 3, 1986, p. 84. en enero de 1987 reunió a 800 delegados deorganizaciones civiles y sigue teniendo gran peso; otra experiencia importante fue el Frente Nacional de Concertación que agrupó a 57 organizaciones en la lucha electoral de 1987. Como veremos más adelante, en el último año se formaron otras alianzas que han adquirido presencia y peso políticos.

A pesar de las limitaciones, la intimidación y represión, las fuerzas opositoras lograron arrancar a los regímenes posdictatorialesimportantes conquistas. El primer gran logro es sin duda el texto constitucional, aprobado en un plebiscito en marzo de 1987. El CNG había intentado controlar la Asamblea Constituyente, elegida en octubre de 1986 con una escasa participación de 5\% del electorado, pero no pudo impedir que la Asamblea redactara un texto liberal que contiene importantes innovaciones: prevé la elección, cada cinco años, de un presidente que no podría ser reelecto en forma inmediata y que debería nombrar un primer ministro del partido mayoritario del parlamento, introduce una segunda cámara al Congreso, abroga la pena de muerte "en toda materia", declara el créole como segundo idioma oficial del país, permite la existencia irrestricta de partidos políticos, sindicatos y asociaciones, somete a los integrantes del ejército a la justicia civil en caso de un crimen cometido en contra de civiles, declara a la policía como fuerza independientedel ejército, sustrae la organización de las elecciones generales de las manos del Ministerio del Interior y la pone en manos de un consejo independiente de nueve miembros. El artículo 291 prohíbe el ejercicio de función pública alguna, durante diez años, 1) a toda persona notoriamente conocida por haber sido - por exceso de celo- uno de los artesanos de la dictadura y de su mante- 


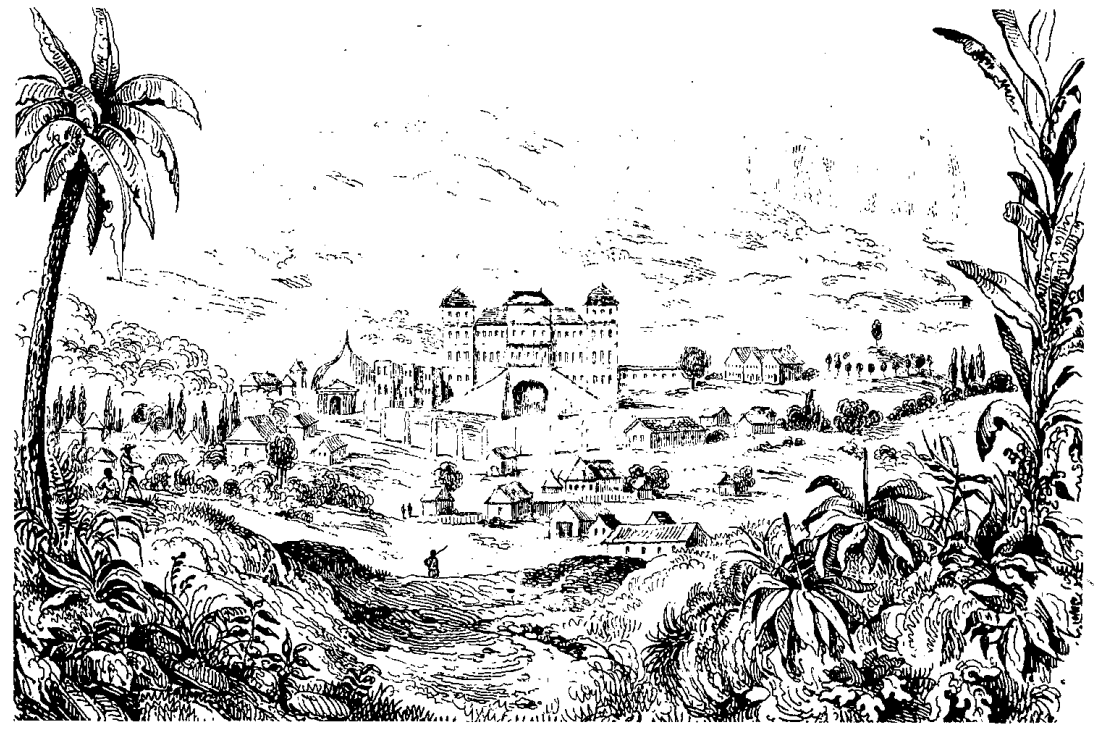

nimiento durante los últimos 29 años; 2) a todo gestor de fondos públicos durante los años de la dictadura sobre el que pese presunción de enriquecimiento ilícito; 3) - a toda persona denunciada por el clamor público de haber practicado la tortura a presos políticos, en ocasión de arrestoso investigaciones $\mathrm{o}$. de haber cometido asesinatos políticos. ${ }^{20}$

El siguiente paso en el tortuoso camino hacia la democracia fue la conformación del consejo electoral independiente cuyos miembros representaban a las Iglesias, la prensa, la universidad, el poder judicial, organizaciones en pro de los derechos humanos y, por supuesto, el Consejo Nacional de Gobiemo. Éstetrató, sin embargo, de impedir la preparación de elecciones libres. En junio de 1987

20 "La Constitución de Haití de 1987", El Caribe Contemporáneo, núm. 18, enero-junio de 1989 , p. 99. limitó las funciones del Consejo Electoral Provisional (CEP), provocando una ola de protestas; su represión -con un saldo de por lo menos 30 muertos- inauguró el clima de violencia que precedió a las elecciones de noviembre.

Cinco candidaturas de la oposición destacaron en el proceso electoral de 1987: la de Gérard Gourgue, que representaba el Frente Nacional de Concertación, de Sylvio Claude, Leslie Manigat, Louis Déjoie y Marc Bazin, candidato favorito de Estados Unidos. Sus campañas fueron cortas y tuvieron que realizarse en medio de un clima político angustiante (después del asesinato de dos candidatos presidenciales). Sin embargo, la suspensión de las elecciones hubiera frustrado las expectativas que se tenían en estos comicios, los primeros después de tres décadas. El 19 de noviembre, las casillas electorales se abrieron ante una afluencia grande de votan- 
tes, pero a las pocas horas, el CEP tuvo que anunciar la suspensión de la votación después de que enuna violenta agresión, perpetrada por fuerzas paramilitares, por lo menos 34 personas perdieron la vida.

En los siguientes comicios, realizados el 17 de enero de 1988, votó únicamente $10 \%$ del electorado. Los cuatro candidatos con mayores posibilidades habían anunciado su boicot, de manera que el CNG podía manipular a su antojo las elecciones, mismas que "favorecieron" a Leslie Manigat.

Durante 1989 , por otra parte, las fuerzas democráticas ganaron espacio político. El gobierno de Avril tuvo que ceder ante la presión opositora e instalar un nuevo consejo electoral en abril; pero no fue sino hasta noviembre cuando le fueron asignadas oficinas permanentes al CEP-2, de manera que entonces pudo iniciar formalmente sus labores. Así, a pesar de sus repetidas declaraciones en favor de unas elecciones libres y de su insistencia en que él sólo representaba un gobierno transitorio, quedó de manifiesto la actitud vacilante de Avril frente a un proceso democratizador serio.

En septiembre, un calendario electoral para 1990 anunció que contemplaba la inscripción de los tres millones de votantes entre enero y marzo, la celebración de elecciones comunales y municipales en abril, los comicios legislativos para julio-agosto y los presidenciales para octubre-noviembre. El anuncio de los comicios puso en marcha la movilización partidaria de la oposición; tres partidos ccntristas, PAIN, MOP y MDN, formaron una alianza electoral bajo el nombre de Unión Nacional y asumieron una actitud crítica frente al calendario electoral propuesto. Con el apoyo de importantes organizaciones obreras y cívicas que se integraron a la alianza (además del PDCH, el PUCH y otros parti- dos menores) la Unión Nacional realizó el 27 de septiembreuna jornada de huelga contra la política del FMI impuesta a Haití. Una segunda alianza, la Alianza Nacional para la Democracia y el Progreso (ANDP), con miras a las elecciones, se formó entre Marc Bazin, Serge Gilles y Dejean Belizaire del Movimiento Nacional Progresista (MNP-28). Esta alianza cuenta con un fuerte apoyo del exterior; Francia y Estados Unidos simpatizan sobre todo con Bazin y Gilles como posibles candidatos presidenciales.

\section{LA CRECIENTE DESLEGITIMACIÓN DEL REGIMEN DE AVRIL}

Durantelosúltimos meses del año pasado la situación político-social conoció un nuevo deterioro. Las medidas de austeridadeconómica anunciadas en septiembre para cumplir los dictámenes del FMI incluían el aumento de productos básicosy servicios y llevaron a una creciente desestabilización de la gourde. Durante las movilizaciones de protesta fueron arrestados tres líderes y presentados posteriormente ante las cámaras de televisión con visibles marcas de tortura. Este acto de represión, ejecutado con un cinismo inaudito, hizo crecer las manifestaciones antigubernamentales. El arresto y maltrato de los líderes populares mencionados constituyó un hito en la escalada de violencia que vivía el país deṡde mediados del año. Constantemente había denuncias sobre abusos cometidos por Tontons Macoutes "desempleados" que actuaban impunemente en Puerto Príncipey en el campo, dirigiéndose sobre todo contra jóvenes y campesinos.

A raíz de la creciente inseguridad, la burguesía liberal se sumó a las protestas populares; Avril ya no parecía garantizar este mínimo de orden administrativo y 
estabilidad monetaria necesarios para sus actividades. ${ }^{21}$ En estas circunstancias, Jean Claude Roy, hombre de negocios que encabeza la agrupación político-civil Unión de Constitucionalistas Haitianos, declaró "El gobiemo toma medidas un día y las contradice al siguiente. [...] Hay un caos total, una desorganización total. No tenemos gobierno." 22 También la alta jerarquía eclesiástica se distanció del régimen y denunció las constantes violaciones de los derechos humanos. ${ }^{23}$

A la deslegitimización interna sesumó el enfriamiento de las relaciones con Estados Unidos. El provocativo acto de Avril de no recibir a fines de noviembre al nuevo embajador estadunidense, Alvin Adams, para la presentación de las cartas credenciales, contribuyó a aumentar la tensión entre ambos paises. "Avril practica un nacionalismo sin nación", escribe al respecto el semanario Haiti en Marche, ${ }^{24}$ mientras que la prensa gubernamental alaba el valiente nacionalismo del presidente. En diciembre, por otra parte, Avril cambia de táctica: anuncia la formación de un "pacto social" y ofrece una política de "concertación" con la oposición. ${ }^{25}$

Este ir y venir entre actos de represión ejecutados con cinismo y promesas de democratización domina también la acción gubernamental en enero y febrero del año en curso. A raíz de una carta de

${ }^{21}$ Haiti Observateur, 6-13 de diciembre de 1989, p. 16.

${ }^{22}$ Don Bohning, "Once 'best hope' for Haiti, leader now seen as obstacle", Miami Herald, 6 de noviembre de 1989, en ISLA, noviembre de 1989 , p. 211.

${ }_{23}$ "Après avoir montré ses griffes, le gouvernementd'Avril veut faire pattes de velours, "HaitiObservateur, 6-13 de diciembre de 1989, p. 16.

${ }^{24}$ Haiti en Marche, 6-12 de diciembre de 1989, p. 1

${ }^{25}$ Haiti Observateur, 6-13 de diciembre de 1989, p. 2. protesta que los opositores envían al gobierno de Taiwán, donde se encuentra de visita como jefe de Estado, Avril fustiga a su regreso a los "elementos apátridas". ${ }^{26}$ Poco después, el asesinato de un miembro de la guardia presidencial y de su familia desencadena una nueva ola de represión; los arrestos con lujo de violencia, los destierros de los opositores y la imposición del estado de sitio durante diez dias destruyen en definitiva la confianza y esperanza que pudieran tener todavía algunos sectores que se oponen al rêgimen. En protesta por la brutal represión, el embajador en Washington, François Benoit, renuncia y declara a la prensa "Avril ha caído bajo la influencia de la extrema derecha duvalierista radical ${ }^{27}$ y Serge Gilles, uno de los opositores más afectados por la violencia, opina: "Avril ha atacado la oposición moderada, la más peligrosa a sus ojos." ${ }^{28}$

"Espero que la lección haya sido aprendida", declaró Avril después de este último episodio de represión, para en seguida volver a presentarse como "hombre de diálogo" y "buena fe democrática"29 y reiterar su voluntad de organizar las elecciones conforme al calendario anunciado. Sin embargo, las esperanzas de comicios honestos parecían insostenibles frente a las acciones tiránicas con que Avril golpeó a la oposición en su conjunto. Las elecciones, aunque planeadas en sus detalles técni$\cos$, amenazaban con ser de nuevo una farsa o, en el peor de los casos, que se repitieran los sucesos trágicos de noviembre de $1987 .{ }^{30}$ Es por ello que las manifestaciones en contra de los planes

${ }^{26}$ Le Monde, 17 de enero de 1990.

${ }^{27}$ Le Monde, 24 de enero de 1990.

${ }^{28}$ Ibid.

${ }^{29}$ Le Monde, 27 de enero de 1990.

${ }^{30} \mathrm{El}$ padre Aristide, entrevistado por Radio Antillas el 29 de noviembre de 1989, no veía la posi- 
electoreros de Avril se intensificaron en lasúltimassemanas de febrero, creciendo además la exigencia de su retiro.

La incertidumbre que reinaba en Haití en el momento de la celebración del ciclo de mesas redondas "América Latina a la hora de las elecciones" daba pie a consideraciones poco optimistas con respecto a elecciones prontas y limpias. Avril se enfrentaba a un rechazo prácticamente unánime por parte de la sociedad civil; carecía de apoyo externo (Estados Unidos, Francia y Canadá se habían distanciado y habían endurecido el tono de sus críticas a las recientes violaciones de los derechos humanos, perpetradas por el régimen haitiano) ${ }^{31} \mathrm{y}$ la oposición interna mostraba cada vez mayores signos de unión y fuerza de presión. Sin embargo, se temía que Avril tratara de conservar el poder a toda costa y se conocían sus escasos escrúpulos en eltratamiento de toda voz disidente, tanto en el seno de las fuerzas armadas, como en el de la oposición política. Pero de nuevo, como ha ocurrido a menudo en el país durante los últimos años, el desenlace de la crisis coyuntural resultó ser del todo impredecible. ${ }^{32}$ Avril no sólo optó por renunciar a la presidencia de facto,

bilidad de elecciones honestas y creíbles. “Estas no pueden ser serias en el contexto actual en el que los criminales están armados y tienen cómplices en el gobierno, disponen de mucho dinero y tienen la experiencia del crimen...Mientras no sean juzgados y reciban su castigo merecido, celebrar elecciones, es pena perdida", declaró a la estación radiofónica. (Haiti Progrès, 6-12 de diciembre de1989, p. 7.)

${ }^{31}$ Le Monde, 24 de enero de 1990.

${ }^{32}$ Maingot habla de la propensión excepcional del sistema político haitiano a operar de manera impredecible. Cfr. Anthony P. Maingot, "Haiti: problems of a transition to democracy in an authoritan soft state", Journal of Interamerican Studies and World Affairs, vol. 28, invierno de 19861987, p. 90. sino que abandonó la isla en un avión de la fuerza aérea estadunidense, puesto a su disposición por razones "humanitarias" y en un esfuerzo por "evitar un mayor baño de sangre", como señaló el Departamento de Estado estadunidense. ${ }^{33}$

\section{PERSPECTIVAS}

En el contexto de la crisis posdictatorial y transición democrática, la caída de Avril reviste enorme importancia: marca un paso decisivo en el proceso de desduvalierización y de fortalecimiento de los elementos civiles como fuerzas políticas determinantes. Significa al mismo tiempo un hito en el proceso de desintegración de las fuerzas armadas y de su debilitamiento como detentores "monopólicos" del poder político. El juramento de lealtad que los altos mandos militares prestaron de manera individual al gobierno civil, resultó ser un acto simbólico de gran trascendencia para la historia política del país.

No obstante, sigue en pie la amenaza al futuro orden democrático que presen$\tan \operatorname{los} 7000$ efectivos del ejército y los cientos de hombres armados que integran las fuerzas paramilitares. El grado de descomposición, degradación y violencia en las filas del ejército es tal que su control y sumisión al orden institucional resulta extremadamente difícil en un futuro próximo. Lo que es cierto para los integrantes del ejército, lo es en grado mayor para las fuerzas paramilitares que constituyen un temible factor de desestabilización del gobierno civil, creado el 13 de marzo pasado.

\footnotetext{
33 José Manuel Nava, "Rescata un avión de EU al general Avril", Excélsior, 13 de marzo de1990, p. 29.
} 
Por otra parte, las tareas de transición democrática se deben realizar sobre un trasfondo de crisis económica profunda que hace al pais dependiente en alto grado de la ayuda exterior. Al mismo tiempo desempeña un papel primordial la actitud del gobierno estadunidense, interesado en evitar una prolongada desestabilización política en la isla caribeña. Establecer una "democracia controlada" en el país vecino a Cuba resulta ser, en la coyuntura actual, de interés estratégico para la política exterior de Estados Unidos con respecto a la región caribeña. La instalación de un gobierno electo, siguiendo el modelo reciente de Nicaragua contribuiría al aislamiento de Cuba en el ámbito latinoamericano. Sin embargo, no queda del todo excluida la "vía panameña" de imponer un orden "democrático", en el caso de que la situación interna se deteriore excesivamente. Por otra parte, en el marco deuna política cada vez más agresiva hacia Cuba aumenta el valor estratégico de Haiti. Así persisten los esfuerzos estadunidenses para establecer una base militar en el puerto Môle Saint Nicolas, situado frente a la bahía de Guantánamo. El papel desempeñado por el personal diplómatico estadunidense en momentos clave del proceso político de Haití en los últimos años muestra que la actitud de su gobierno constituye un factor de gran peso en todo cambio que se produce en el país.

En resumen, las perspectivas que se abrieron con la caida de Avril y el nombramiento de Ertha Pascal Trouillot como presidenta interina, son esperanzadoras; por primera vez, desde la caída de Baby Doc, un cambio de gobiemo es producto de la lucha político-social y no de rivalidades internas en las fuerzas armadas, ni de la imposición y manipulación por parte de los altos mandos militares. La

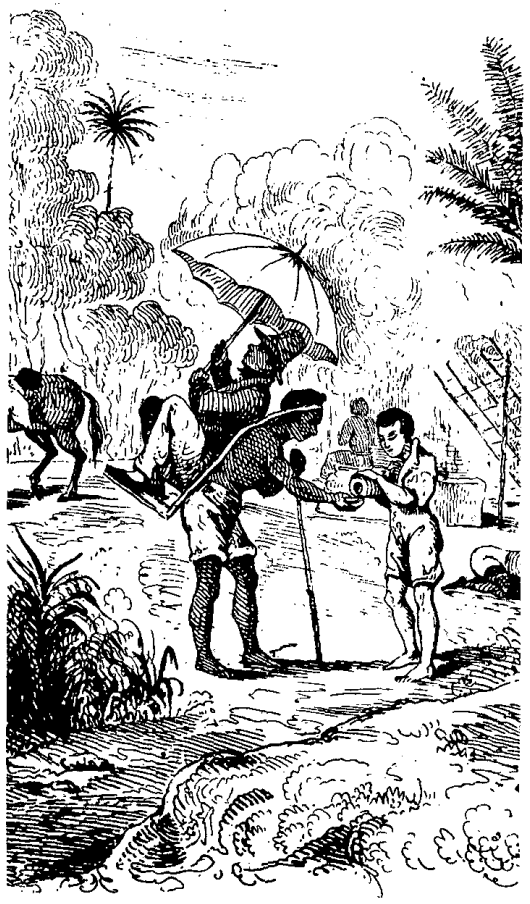

energía de lucha antidictatorial, lejos de disminuir, se ha incrementado durante las semanas de represión de enero y febrero; las fuerzas democráticas salieron fortalecidas de esta última fase de resistencia al dominio militar. Se espera que con ello se abra una nueva etapa de la historia política del pais, en la que la celebración de elecciones y la transición hacia un orden democrático parecen estar más cerca que nunca. 

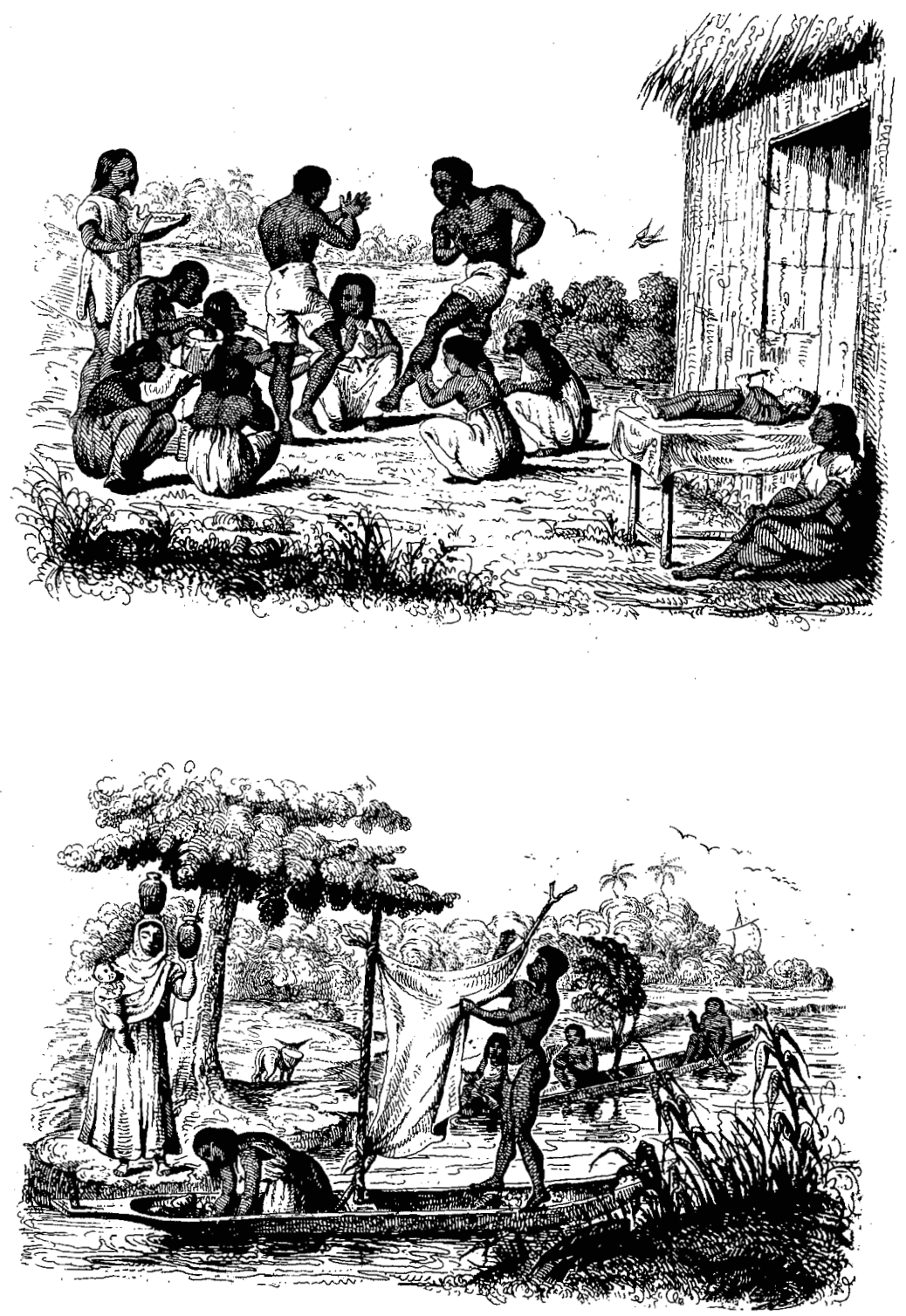